\title{
A pediatric case with an unstabilized neck treated with skeletal muscle electrical stimulation and KAATSU training ${ }^{\circledR}$
}

\author{
H. Iwashita
}

Int. J. KAATSU Training Res. 2015; 11: 7-12

Correspondence to: H. Iwashita,

Komone Acupuncture Clinic 3-10-18 Mukaihara, Itabashi-ku, Tokyo, 173-0036, Japan

iwashita@komone.jp

See end of article for authors' affiliations
[Objectives] In recent years, a larger percentage of children qualify as physically or mentally challenged (challenged children, hereafter) and neck stabilization is a major issue in this population. We performed belt electrode skeletal muscle electrical stimulation (B-SES) in combination with KAATSU training, in a severely challenged child with lissencephaly to investigate treatment safety and how this might be effective in achieving neck stabilization. We present our results below.

[Methods] A patient with lissencephaly was treated twice a week for 15 weeks with B-SES and KAATSU training on an outpatient basis. Using the growth and development stage and Ushijima's (1996) neck stabilization evaluation criteria for children with Severe Motor and Intellectual Disabilities, we assessed our patient based on recorded videos.

[Results] In a challenged child with severe motor developmental delay who was unable to take part in voluntary training, upper body KAATSU training with B-SES led to increased muscle tone and improved neck stabilization.

[Conclusions] B-SES with KAATSU training may be an effective treatment for children with severe physical and mental challenges who lack signs of neck stabilization. However, it will be necessary to study this treatment in a larger number of cases using more assessment methods in the future.

Key words: lissencephaly, neck stabilization, KAATSU training, skeletal muscle electrical stimulation

\section{INTRODUCTION}

Severely challenged children are defined as children who suffer a combination of severe mental and physical challenges. Rehabilitation in these severely challenged children is difficult since spontaneous training is hard to establish and they will not be responsive to various instructions, etc. so that compared to children with other types of challenges, acquisition of training movements is difficult. Ordinarily in an infant, the neck stabilizes at around 4 months of age, and this provides the foundation for further motor development. This factor is thought to often impact subsequent motor development (Kawaguchi et al., 2006). However, there are currently no effective rehabilitation methods for those infants and children whose necks have not stabilized. We instituted KAATSU training in a patient with lissencephaly and succeeded in achieving neck stabilization in a patient with flaccid quadriplegia, and herein report our experience.

\section{Research-related concerns}

This research was conducted with the consent of the patient's primary physician, and before starting this study, we provided the parents with information about this treatment and confirmed that they gave their consent.

\section{Case}

Patient: A 2 year- 4 month-old boy.

Diagnosis: Lissencephaly (broad gyrus),

West syndrome

Chief complaint: flaccid quadriplegia

Family history: no remarkable findings.

Past medical history: During pregnancy, there were no particular abnormalities and the patient was delivered vaginally at 38 weeks 6 days weighing $2680 \mathrm{~g}$.

History of present illness:

The patient had severe flaccid quadriplegia, spending most of his life bedridden and was barely able to turn over on his own. He required full assistance for both meals and elimination. Mild joint contractures were noted in both hands and feet and it was difficult for him to control his muscles. Although he could not understand or communicate through language, he was able to express his feelings through facial expressions. He was experiencing 5 to 10 epileptic seizures a day. 


\section{Methods}

a) Exercise conditions

KAATSU belts were wrapped around the uppermost areas of the axillary and femoral regions, and the KAATSU master (KAATSU Japan CO., Ltd.) was employed. Simultaneously, belt electrode -skeletal muscle electrical stimulation (B-SES, Homer ion Institute, Inc.) belts (Hamada et al., 2004) were wrapped around the thorax-brachial-antebrachial/ epigastric-lower abdominal areas. B-SES is an EMS device that allows musculature in all areas between the belts to be exercised as a substitute for active exercise (Fig. 1). B-SES is characterized by exercising more muscles than traditional EMS and there is less pain induced by electrical stimulation and thus it can be used in children without placing too much of a

(a) Traction Response

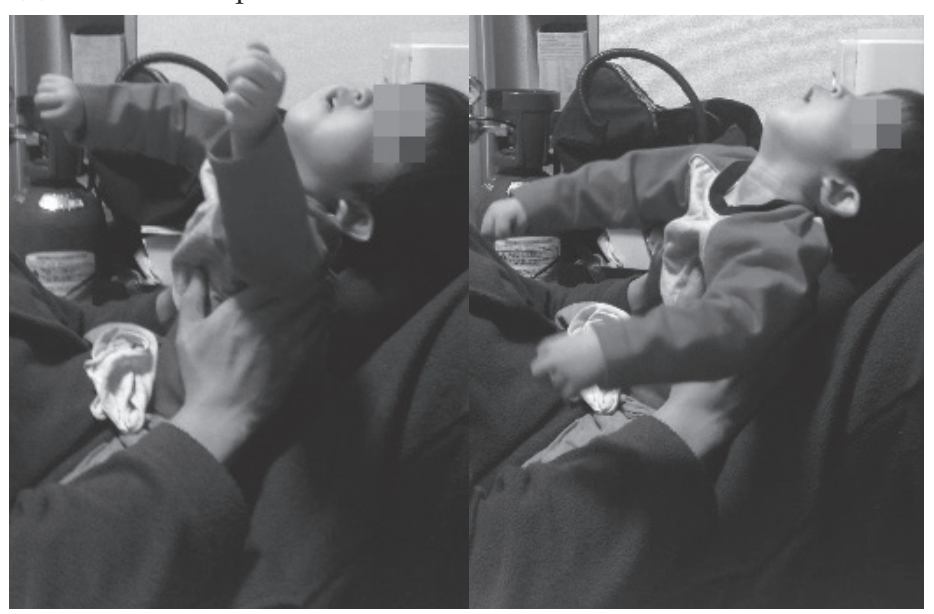

(b) Sitting tonic labyrinthine reflex

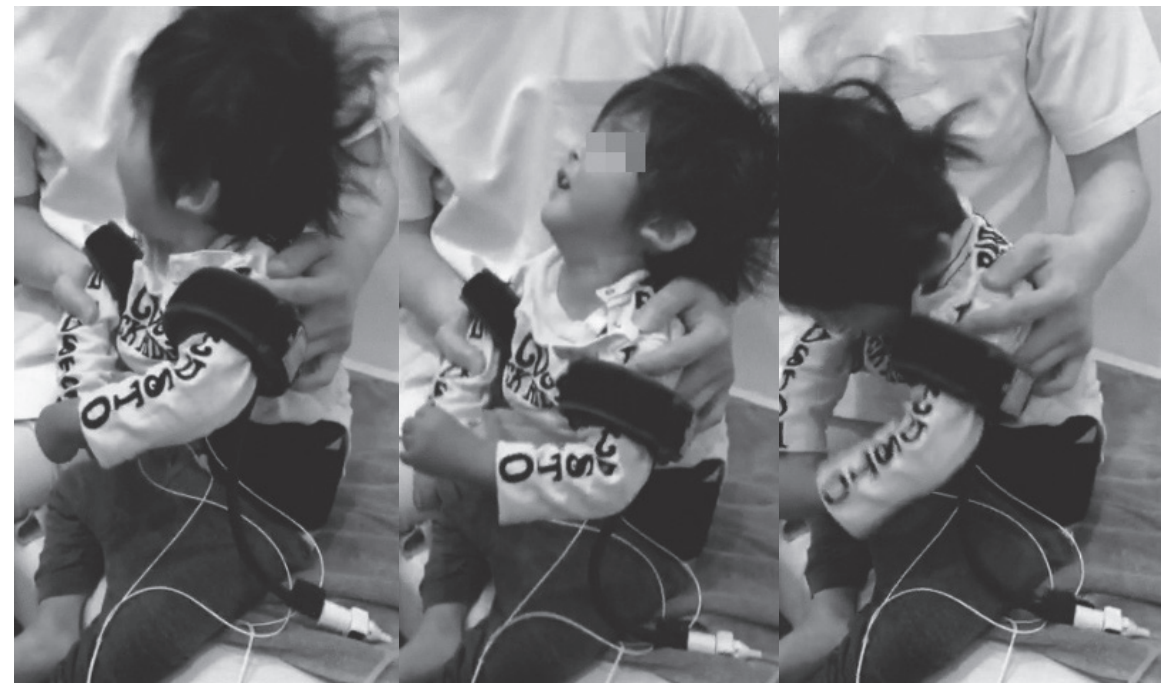

(c) Spontaneous movement

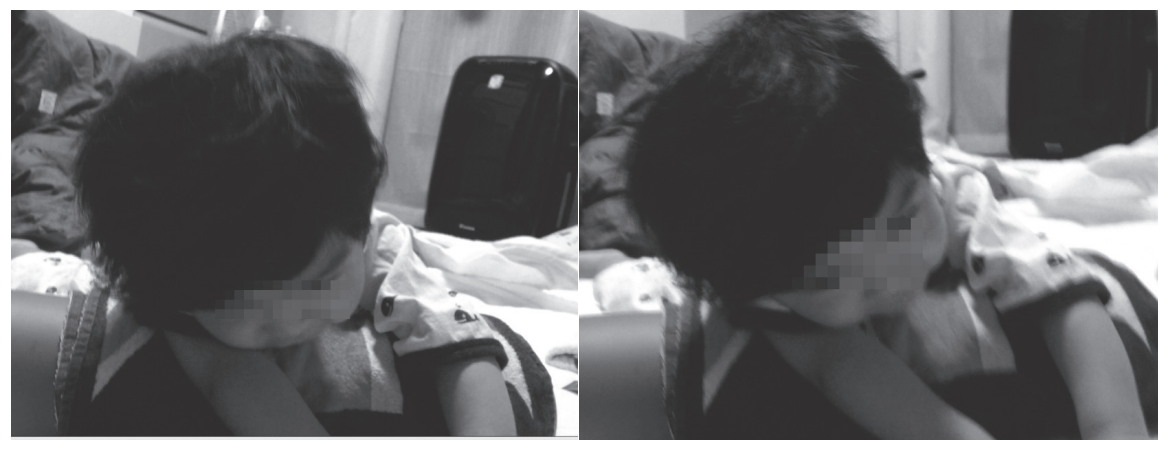

Fig. 1. Before KAATSU training 
burden on them. Upper arm training was started at a Base Standard KAATSU Units (SKU) pressure of 30$40 \mathrm{SKU} /$ optimal pressure 60-70SKU. Since this patient could not talk, we determined the appropriate pressure based on the color of the hands, pulse, and the child's facial expressions. After deciding on the optimal pressure, pressurization and depressurization was repeated 3 times, and after passive ROM training, B-SES was applied. B-SES intensity was the minimum intensity at which muscular contraction could be confirmed (11-15 mA), and this was continued for 10 minutes. In addition, during training, we carefully kept the patient under observation for any changes in his physical state. During depressurization, we made sure that his head was kept lower than the heart to minimize any vagal reflex.

\section{b) Evaluation}

1) Evaluation of neck stabilization in a child with severe mental and physical challenges during development

Evaluation was made in accordance with Ushijima's (1996) neck stabilization evaluation criteria for children with Severe Motor and Intellectual Disabilities. Assessed items were traction response, tonic labyrinthine reflex while seated, and spontaneous movement on elbows. Although various kinds of tests are used to assess neck stabilization, we used the most common items to measure primarily spontaneous movement. Procedures and evaluation criteria are shown in Table 1. The patient was evaluated, compared, and investigated before the start of KAATSU training and after 15 weeks of treatment.

\section{2) Videos}

Cerebral palsy in severely challenged children leads to delays in motor development, maturation of sensation perception, and cognition, excess muscle tone resulting in abnormalities in the posture tone, and various other factors complicating the issue (Bax et al., 2005). For this reason, the mechanism of action is difficult to assess, so evaluating videos made it possible to conduct a more comprehensive evaluation and investigation.

\section{Results}

\section{Results of neck stabilization assessment in a child with severe mental and psychological challenges.}

Results from our patient are shown in Table 2. If we focused on changes in scores for each of the evaluation items, there were only minor increases of 1 to 2 points each, which made it seem as if not much had changed. However, we studied these evaluation criteria in further detail. First, looking at the traction response, the patient could not move his head at all and was described as, "no head lag was observed"

Table 1. a: Traction Response b: Sitting tonic labyrinthine reflex c: Spontaneous movement on elbows

\begin{tabular}{|c|c|c|}
\hline & Procedure & Assessment criteria \\
\hline $\mathrm{a}$ & $\begin{array}{l}\text { Child is placed in a supine position symmetrical on both } \\
\text { sides. Trying to avoid touching the back of the child's } \\
\text { hands, touch the palms with thumbs and hold the wrists. } \\
\text { Then while calling out to the child, slowly pull the child up } \\
90 \text { degrees into a sitting position. }\end{array}$ & $\begin{array}{l}\text { I. head lag not observed. } \\
\text { II. traction response } 45 \text { degree head lag observed. } \\
\text { III. }<30 \text { degree head lag observed. } \\
\text { IV. head control observed. }\end{array}$ \\
\hline $\mathrm{b}$ & $\begin{array}{l}\text { Have the child sit with both sides aligned symmetrically } \\
\text { and bring the trunk up into an upright position and observe } \\
\text { how well the child can maintain this position on his own. }\end{array}$ & $\begin{array}{l}\text { I. Head goes back } \\
\text { II. Head remains upright } 1 \text { or } 2 \text { times. } \\
\text { III. Head remains upright more than } 3 \text { seconds. } \\
\text { IV. Head remains upright more than } 5 \text { seconds. } \\
\text { V. Head remains upright more than } 10 \text { seconds. }\end{array}$ \\
\hline $\mathrm{c}$ & $\begin{array}{l}\text { Have the child on his elbows and while drawing his } \\
\text { attention by calling, or using a toy or electronic sound, } \\
\text { record the response. See if he raises his head and measure } \\
\text { how long he can maintain this position. }\end{array}$ & $\begin{array}{l}\text { I. No response or movement. } \\
\text { II. Rotates laterally. } \\
\text { III. Raises head } 1 \text { or } 2 \text { times. } \\
\text { IV. Can raise head up and maintain position more than } 3 \\
\text { seconds. } \\
\text { V. Can keep head up } 15 \text { seconds or longer. }\end{array}$ \\
\hline
\end{tabular}

Table 2. Results of neck stabilization assessment

\begin{tabular}{|l|r|rl|}
\hline & \multicolumn{2}{|c|}{ Baseline } & \multicolumn{2}{c|}{ After 15 weeks } \\
\hline Traction Response & $1 / 4 \quad(25 \%)$ & $2 / 4$ & $(50 \%)$ \\
\hline Sitting tonic labyrinthine reflex & $2 / 5 \quad(40 \%)$ & $4 / 5$ & $(80 \%)$ \\
\hline Spontaneous movement & $2 / 5 \quad(40 \%)$ & $4 / 5$ & $(80 \%)$ \\
\hline Total & $5 / 14 \quad(36 \%)$ & $10 / 14 \quad(71 \%)$ \\
\hline
\end{tabular}


before the start of treatment. After 15 weeks, "traction response is observed with a $45^{\circ}$ head lag" showing the patient was now able to move against gravity. The tonic labyrinthine reflex while seated was described as "the head returns to an upright position once or twice" showing the patient was able to move against gravity, but this was a singular movement and lacking in control. However, after 15 weeks, this movement was also evaluated as "Can maintain the head in an upright position for 5 seconds or longer" and while it could only be seen for a limited time, the patient could now maintain some continuous control. With regard to spontaneous movement on elbows, the patient was described as "rotates laterally" showing the patient was responding to the noise stimuli but the head remained down and the patient could not move against gravity. After 15 weeks, however, the patient was able to resist gravity and "could raise his head and hold a position for 3 seconds or longer" and his response to sound stimuli also improved. Scores for all items had increased, and when content was considered, this boy was now able to move against gravity, suggesting muscle strength, muscle endurance, and muscle tone may have improved with treatment.

\section{Evaluation using videos}

Images from before KAATSU training was started are shown in Fig. 1. There is an overall lack of muscle tone and the joints are loose. However, in the arms, increased muscle tone was noted in the brachial flexor

(a) Traction Response

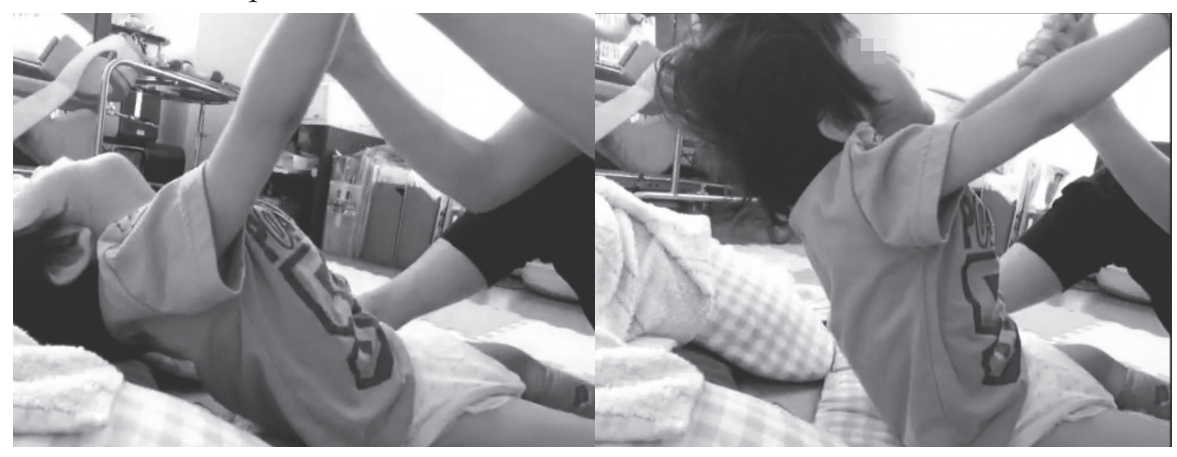

(b) Sitting tonic labyrinthine reflex

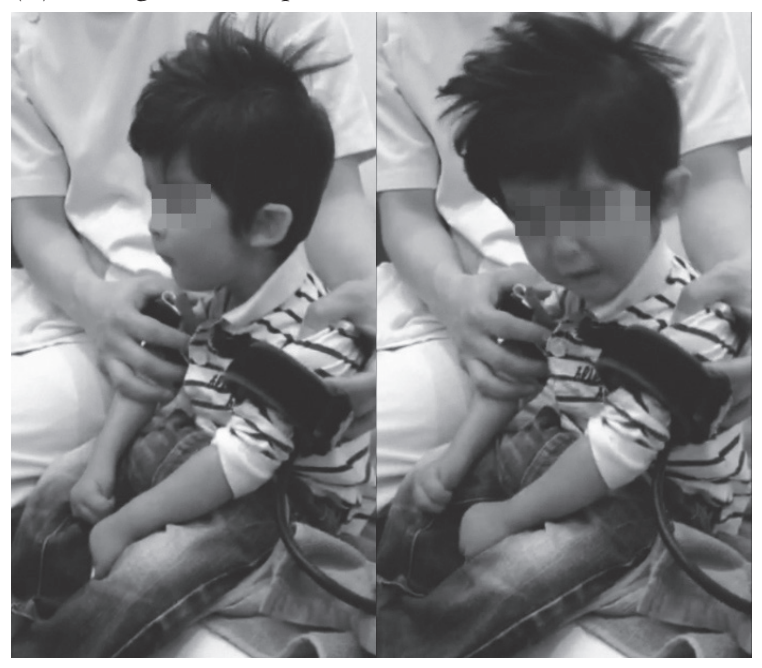

(c) Spontaneous movement

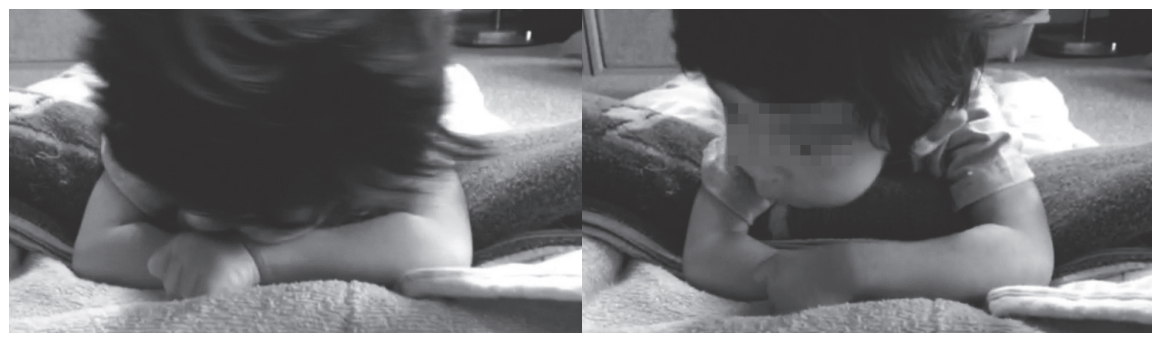

Fig.2. After 15 weeks of KAATSU training 
muscle group and forearm radial flexor muscle group, flexor digitorum superficialis and flexor digitorum profundus, adductor hallucis muscle, and pronator muscle. In the legs, increased muscle tone of the leg muscles, medial hamstrings, adductor magnus muscle group and iliopsoas muscle were observed. Fig. 1 shows the items listed for evaluation 1 that were recorded on video. However, when testing for a traction response, since there was a risk of neck and shoulder joint subluxation and sprain, the test is conducted while supporting the boy's abdomen (Fig. la). The palmar response was very strong, with elbow joint flexion and strong muscle tightness, but even when the upper arms were supported, the neck would tilt forward or backwards (Fig lb). In a prone position, lateral rotation of the neck was present, but this was mostly a result of the boy twisting his trunk rather than a movement of the neck.

Next, Fig. 2 shows the child 15 weeks later. Range of motion of the shoulder joint has increased, traction response was stronger, and evaluation while firmly holding the wrists was now possible. A traction response of a $45^{\circ}$ head lag was observed (Fig. 2a). In addition, although the patient continued to have tight fists, the elbow joint was more extended compared to before training, and the neck could be maintained in a midline position. In addition, although it was only slight, the patient could now rotate to some degree (Fig. 2b). In the prone position, muscle contraction of the lumbar dorsal area was more prominent compared to before the start of treatment and although his body as a whole was relaxed, he was still able to raise his neck (Fig. 2c). These findings suggested muscle tone improvement, enhanced muscle endurance and better muscle control compared to before the start of training.

\section{Discussion}

An extremely important point in this patient is whether our findings were actually the result of KAATSU training or the patient's natural growth and maturation. This patient suffered from lissencephaly complicated by West syndrome, and was unable to maintain neck stability until 2 years and 4 months. Lissencephaly refers to a condition where the gyri are broad and the surface of the cerebrum is smooth. It is a type of neuronal migration disorder that occurs during the process where at 6 to 20 weeks of gestation, neurons that have proliferated near the ventricles migrate to the cortex. Patients show signs of low muscle tone from infancy, and after childhood, many of the patients suffer severe motor and psychological challenges. The definition of West syndrome is intractable epilepsy that occurs as a result of various brain dysfunctions during infancy, and is accompanied by delays in psychomotor development. Epileptic spasms (ES) that occur in series, EEG hypsarrhythmia, arrests of psychomotor development, and regression are the 3 distinguishing features. The most common ages for onset are 3 to 11 months of age and it is rare for it to appear after the age of 2 years (Oguni et al., 2013). Based on the above, and taking his age into consideration, it can be speculated that neck stabilization would have been difficult to acquire through a natural maturation process in this patient.

We would like to consider what factors associated with KAATSU training may have been effective in establishing neck stability. In this case, no direct approach was taken to stabilize the neck. That makes it likely that neurological changes and associated muscles strengthening and improvement were involved. As for neurological changes based on this child disease state, changes to the brain itself are unlikely with just short-term training. Here, we would like to suggest atherogenic muscle inhibition (AMI hereinafter) was involved. AMI is a condition where joint restrictions due to injury or contracture inhibit nerve activity of the surrounding muscles causing muscular atrophy (Pietrosimone et al., 2008). Two methods to improve AMI are known: icing and exercising while undergoing electrical stimulation (Hopkins et al., 2001).This means combined use of B-SES and KAATSU training could have led to shortterm improvement. In addition, it has been pointed out that AMI may be caused by intracapsular swelling which led mechanoreceptors to send out inhibitory signals (Rice et al., 2009). This may be due to KAATSU training which can improve peripheral blood circulation. Next, the concurrent muscle strengthening and improvement can be explained using a theory known as anatomy train (Myers, 2012). This refers to

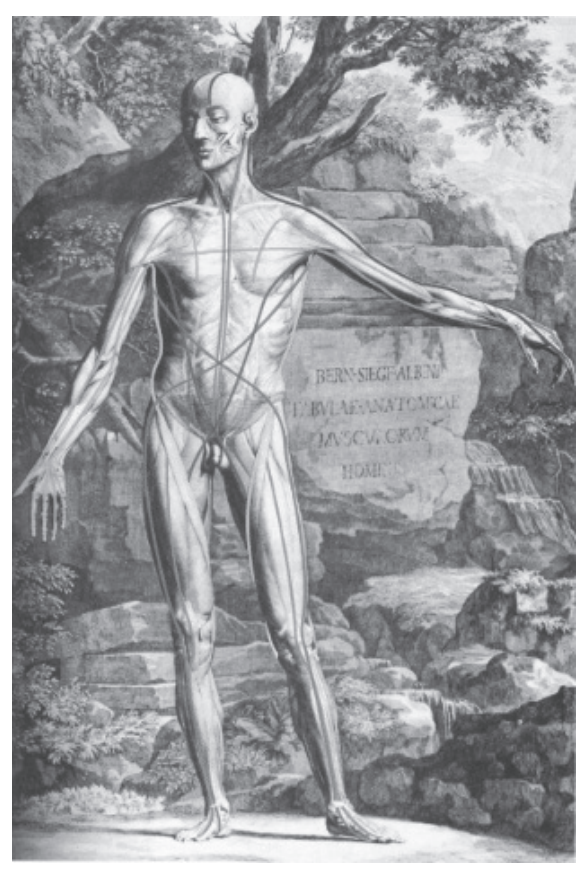

Fig. 3. Anatomy train muscle fascia binding pattern (Myers TW (2012)) 
the fact that although each muscle may be functioning separately, electrical stimuli are sent through fascia and so functionally, these can be considered linked. There are several patterns to these phenomena. Abdominal muscles and anterior cervical areas and brachial muscles are considered to be linked to lateral and posterior cervical areas (Fig. 3). Taking this into consideration, in our case, KAATSU training in combination with B-SES to the upper arms and abdominal areas are thought to have led to muscle enhancement of the neck.

In children with cerebral palsy, muscle training had been contraindicated because it was thought to enhance the risk of spasms, but after 1995 many reports have been published (Damiano et al., 1995; Damiano and Abel, 1998; Kondo et al., 2014), and currently rehabilitation guidelines for cerebral palsy recommend aggressive use of muscle training. Mechanical electrical stimulation is also recommended under these guidelines and so KAATSU training in combination with B-SES is a minimally invasive and safe form of training.

In addition, there are papers reporting that acquisition of neck stability affects IQ (Matsunami et al., 2004) and ultimate motor function prognosis (Maeda and Hayakawa, 2003). In severely challenged children where neck stabilization cannot be observed, a report suggested that concentrated physiotherapy, which is generally said to be effective in gross motor acquisition, may have no effect (Asakura et al., 2000). Furthermore, a secondary dysfunction is painful muscle contraction, and cervical torsion which may lead to progression of obstructive respiratory dysfunction and feeding difficulties with side curvature. Based on the above, stabilization of the neck can have a major impact on a severely challenged child's QOL. Therefore, the use of B-SES together with KAATSU training may be effective in acquiring neck stability which may have a major impact on improving quality of life in a severely challenged child.

\section{Conclusions}

KAATSU training in combination with B-SES may be effective in children in whom neck stabilization cannot be observed, with severe mental and physical challenges. However, it will be necessary to increase the number of cases and evaluation methods to confirm our findings in the future.

\section{References}

1) Asakura Y, Kinoshita S, Nakagomi N, Moriyama A (2000) Examination of the Effects of Rehabilitation in Children with Cerebral Motor Disorders. (in Japanese) Rehabilitation Medicine 37:711-716.

2) Bax M, Goldstein M, Rosenbaum P, Leviton A, Paneth N, Dan B, Jacobsson B (2005) Proposed definition and classification of cerebral palsy. Dev Med Child Neurol. 47:571-576.

3) Damiano DL, Abel MF (1998) Functional outcomes of strength training in spastic cerebral palsy. Arch Phys Med Rehabil. 79:119125.

4) Damiano DL, Kelly LE, Vaughn CL (1995) Effect of quadriceps femoris muscle strengthening on crouch gait in children with spastic diplegia. Phys Ther. 75:658-667.

5) Hamada T, Kimura T, Moritani T (2004) Selective fatigue of fast motor units after electrically elicited muscle contractions. J Electromyogr Kinesiol. 14:531-538.

6) Hopkins JT, Ingersoll CD, Edwards J, Edwards J, Klootwyk TE (2001) Cryotherapy and TENS decrease arthrogenic muscle inhibition of the vastus medialis following knee joint effusion. J Athl Train 37:25-31.

7) Kawaguchi Y, Ninomiya Y, Nakamura T, Okazaki N, Matsuzaka T, Motoyama K, Matsuo M, Koyanagi K, Nagaoka T, Kawasaki C (2006) Attitude of children with cerebral palsy (in Japanese). JOURNAL OF CLINICAL REHABILITATION 15:300-306.

8) Kondo I, Takahashi H, Mitsuru S et al. (2014) Cerebral palsy rehabilitation guidelines, second edition. Japan Association of Rehabilitation Medicine Clinical Practice Guidelines Committee, the Japanese Association of Rehabilitation Medicine Cerebral Palsy Rehabilitation Guidelines Development Ccommittee Eiting, Kaneharashuppan, Tokyo, ppl29-132.

9) Maeda S, Hayakawa S (2003) Prediction of gross motor function prognosis of children with cerebral palsy (in Japanese). Brain and Development 35:144-144.

10) Matsunami S, Kishimoto K, Maeno $Y$ (2004) Influence of positioning on extremely low birth weight infants (in Japanese). Physical Therapy 31:328-328.

11) Myers TW (2012) Anatomy Train - myofascial meridians for manipulative exercise therapy. in Japanese) Second edition, Igaku Shoin, Tokyo, ppl67-224

12) Oguni H, Otsuki T, Sugai K, Inoue Y, Nagai T (2013) Rare intractable epilepsy clinic manual - rare intractable epilepsy clinic manual: Point of diagnosis and characteristics of the disease. (in Japanese) Diagnosis and Treatment, Inc., Tokyo, pp 11-14.

13) Pietrosimone BG, Hopkins JT, Ingersoll CD (2008) The role of disinhibitory modalities in joint injury rehabilitation. Athl Ther Today 13:2-5.

14) Rice D, McNair PJ, Dalbeth N (2009) Effects of cryotherapy on arthrogenic muscle inhibition using an experimental model of knee swelling. Arthritis Rheum. 61:78-83.

\section{Author's affiliations \\ Iwashita H, Komone Acupuncture Clinic, Tokyo, Japan}

The use of KAATSU Training or the term "KAATSU Training" in the body text are registered trademarks of KAATSU JAPAN Co., Ltd.

C2015 KAATSU JAPAN Co., Ltd. 